\title{
Assessment of knowledge, attitudes and practices about adrenal insufficiency in the critically ill among endocrinologists and intensivists practicing in Chennai
}

\author{
A. Sathya, B. Srinivasan, G. Parasuraman, L. Ravikumar, S. Mahadevan, U. Sriram, \\ V. Gopichandran
}

Background: Adrenal insufficiency is a common occurrence in the critically ill and it is essential that intensivists and endocrinologists involved in the care of these patients have a good understanding of the concepts related to this condition. Objectives: To assess the knowledge, attitudes and practices about adrenal insufficiency in the critically ill among the endocrinologists and intensivists practicing in the city of Chennai. Materials and Methods: Questionnaires containing ten questions pertaining to adrenal insufficiency in the critically ill were sent to a total of six endocrinologists and 52 intensivists practicing in Chennai. Results: About $77 \%$ of all the respondents agreed to the fact that adrenal insufficiency is a frequent occurrence in critical illness. But $57 \%$ of them felt that there is no need for routine evaluation of critically ill patients for adrenal insufficiency. Random serum cortisol was selected by $62 \%$ of the responders as the method for evaluating adrenal function in the critically ill. There is clearly no agreement among the endocrinologists or the intensivists on the various cut off levels for diagnosis. Neither is there a clear consensus on the method followed for treatment of patients with adrenal insufficiency in the critical care unit. Conclusion: There is no concordance in the knowledge, attitudes or practices on adrenal insufficiency in the critically ill among the endocrinologists and intensivists in Chennai. There is a need for developing standard diagnostic and treatment guidelines and making it available for all the practicing endocrinologists and intensivists.
\end{abstract}

Key words: Adrenal insufficiency, critically ill, KAP

The subject of adrenal insufficiency in the critically ill is of great interest. Research has led to the understanding of the pathophysiology of adrenal insufficiency in critical illness. Its recognition and management has been shown

\footnotetext{
From:

Associates in Clinical Endocrinology Education and Research (ACEER), Apollo Specialty Hospital Annexe, Mount Road, Chennai, India

Correspondence:

Dr. Usha Sriram, Associates in Clinical Endocrinology Education and Research (ACEER), 319, GEO Towers III Floor, Apollo Specialty Hospital Annexe, Mount Road, Chennai - 600 035, India.

E-mail: drushasriram@gmail.com
}

to alter the outcome in the critically ill patient. In this scenario it has become essential that all endocrinologists and intensivists have a clear understanding of the current guidelines for management of the critically ill with adrenal insufficiency. This questionnaire survey was conducted to assess the KAP of endocrinologists and intensivists about adrenal insufficiency in the critically ill.

\section{Objectives}

- To assess the KAP of endocrinologists and intensivists practicing in the Chennai city, about 
adrenal insufficiency in the critically ill.

- To see if there is a common consensus among the endocrinologists and among the intensivists on the various issues regarding adrenal insufficiency in the critically ill.

\section{Materials and Methods}

The issues relating to adrenal insufficiency in the critically ill were considered. Questions were prepared to address each of the following aspects of adrenal insufficiency in the critically ill.

- Incidence of adrenal insufficiency in the critically ill

- Pathophysiology

- Assessment of adrenal function in the critically ill

- 250 mcg vs 1 mcg ACTH stimulation test

- Treatment of adrenal insufficiency in the critically ill.

The questions were totally ten in number. Adequate number of questions was asked to address all these issues; at the same time the number of questions was kept limited to avoid responder disinterest.

\section{Questions}

1. Adrenal insufficiency is a frequent occurrence in critical illness. True/False

2. Patients in Septic Shock are cortisol deficient. True/ False

3. Evaluation of adrenal insufficiency in critical illness should be routinely performed. True/False

4. How is adrenal insufficiency in critical illness evaluated?

Random serum cortisol
a. $250 \mathrm{mcg}$ ACTH stimulation test
b. $1 \mathrm{mcg}$ ACTH stimulation test
c. ACTH levels

5. The cut off value for random serum cortisol considered normal is?
a. $18 \mathrm{mcg} / \mathrm{dl}$
b. $20 \mathrm{mcg} / \mathrm{dl}$
c. $25 \mathrm{mcg} / \mathrm{dl}$
d. $35 \mathrm{mcg} / \mathrm{dl}$

6. The cut off value of serum cortisol for $250 \mathrm{mcg} \mathrm{ACTH}$ stimulation test at $1 \mathrm{~h}$ is:
a. $18 \mathrm{mcg} / \mathrm{dl}$
b. $20 \mathrm{mcg} / \mathrm{dl}$
c. $25 \mathrm{mcg} / \mathrm{dl}$
d. $35 \mathrm{mcg} / \mathrm{dl}$

7. Treatment of critically ill patients with steroids is based on
a. Cortisol levels
b. Clinical picture
c. Prophylaxis

8. Treatment with steroids is done with:

a. IV hydrocortisone $50 \mathrm{mg} \mathrm{q} 8$ hourly

b. IV Hydrocortisone $100 \mathrm{mg}$ q hourly

c. Oral steroids

d. IV continuous infusion of hydrocortisone

9. Retesting of adrenal insufficiency is done after:
a. 5 days
b. 1 week
c. Once clinically stable
d. After discharge

10. Duration of cortisol treatment is:
a. 5 days
b. 7 days
c. 10 days
d. 2 weeks
e. Up to clinical improvement

These questions were hand delivered to the endocrinologists and intensivists in the city. They were asked to answer the questionnaires and return them in a week's time. Endocrinologists were defined as physicians trained in the field of endocrinology either in India or abroad and practicing active endocrinology in the outpatient and inpatient setting. Intensivists were defined as physicians, surgeons or anesthesiologists who were currently involved in taking care of critically ill patients in intensive care units. Some of the questionnaires were also answered by postgraduate students in training in the field of intensive care. A total of six endocrinologists and 52 intensivists answered and returned the questionnaires.

\section{Results}

The results are tabulated in Tables 1-3.

Some of the physicians did not answer some questions. The percentage of physicians who did not answer the questions was not very big and so is not likely to bring a big change in the results.

About $77 \%$ of all the respondents agreed to the fact that adrenal insufficiency is a frequent occurrence in critical illness. But $57 \%$ of them felt that there is no need for routine evaluation of critically ill patients for adrenal 


\section{Table 1: Knowledge, attitudes and practices on adrenal insufficiency in the critically ill}

\begin{tabular}{|c|c|c|c|c|c|}
\hline S. No. & Question & Response & Endocrinologists $n=6$ & Intensivists $n=52$ & Total $n=58(\%)$ \\
\hline \multirow{2}{*}{1} & Adrenal insufficiency is a frequent occurrence in & Yes & 4 & 41 & $45(77.6)$ \\
\hline & critical illness. & No & 2 & 11 & $13(22.6)$ \\
\hline \multirow[t]{3}{*}{2} & Patients in septic shock are cortisol deficient. & Yes & 3 & 32 & $35(60.3)$ \\
\hline & & No & 1 & 20 & $21(36.2)$ \\
\hline & & No response & 2 & 0 & 2 \\
\hline \multirow[t]{3}{*}{3} & Evaluation of adrenal insufficiency in critical & Yes & 4 & 19 & $23(39.6)$ \\
\hline & illness should be routinely performed. & No & 2 & 31 & $33(56.8)$ \\
\hline & & No response & 0 & 2 & 2 \\
\hline
\end{tabular}

\section{Table 2: Knowledge, attitudes and practices on evaluation of adrenal function in the critically ill}

\begin{tabular}{|c|c|c|c|c|c|}
\hline S. No & Question & Response & $\begin{array}{l}\text { Endocrinologists } \\
n=6\end{array}$ & $\begin{array}{l}\text { Intensivists } \\
n=52\end{array}$ & $\begin{array}{l}\text { Total } \\
n=58(\%)\end{array}$ \\
\hline \multirow[t]{4}{*}{1} & \multirow[t]{4}{*}{ Evaluation is done by? } & Random serum cortisol & 3 & 33 & $36(62)$ \\
\hline & & 250 mcg ACTH stimulation test & 3 & 14 & $17(29.3)$ \\
\hline & & $1 \mathrm{mcg}$ ACTH stimulation test & 0 & 8 & $8(13.8)$ \\
\hline & & ACTH levels & 0 & 2 & $2(3.4)$ \\
\hline \multirow[t]{5}{*}{2} & \multirow[t]{5}{*}{ Cut off value for random serum cortisol is? } & $>18 \mathrm{mcg} / \mathrm{dl}$ & 3 & 23 & $26(44.8)$ \\
\hline & & $>20 \mathrm{mcg} / \mathrm{dl}$ & 0 & 11 & $11(18.9)$ \\
\hline & & $>25 \mathrm{mcg} / \mathrm{dl}$ & 2 & 12 & $14(24.1)$ \\
\hline & & $>35 \mathrm{mcg} / \mathrm{dl}$ & 0 & 2 & $2(3.4)$ \\
\hline & & No response & 1 & 4 & 5 \\
\hline \multirow[t]{5}{*}{3} & \multirow{5}{*}{$\begin{array}{l}\text { Cut off value of serum cortisol after } 1 \text { hour } \\
\text { in the } 250 \mathrm{mcg} \text { ACTH stimulation test is? }\end{array}$} & $>18 \mathrm{mcg} / \mathrm{dl}$ & 4 & 8 & $12(20.6)$ \\
\hline & & $>20 \mathrm{mcg} / \mathrm{dl}$ & 0 & 11 & $11(18.9)$ \\
\hline & & $>25 \mathrm{mcg} / \mathrm{dl}$ & 0 & 14 & $14(24.1)$ \\
\hline & & $>35$ mcg/dl & 2 & 13 & $15(25.8)$ \\
\hline & & No response & 0 & 6 & 6 \\
\hline
\end{tabular}

Table 3: Knowledge, attitudes and practices on treatment of adrenal insufficiency in the critically ill

\begin{tabular}{|c|c|c|c|c|c|}
\hline S.No & Question & Response & $\begin{array}{l}\text { Endocrinologists } \\
n=6\end{array}$ & $\begin{array}{l}\text { Intensivists } \\
n=52\end{array}$ & $\begin{array}{l}\text { Total } \\
n=58\end{array}$ \\
\hline \multirow[t]{3}{*}{1} & \multirow{3}{*}{$\begin{array}{l}\text { Treatment of critically ill patients with } \\
\text { steroids is based on? }\end{array}$} & Cortisol level & 4 & 20 & $24(41.4)$ \\
\hline & & Clinical picture & 2 & 28 & $30(51.7)$ \\
\hline & & Prophylactic & 0 & 4 & $4(6.8)$ \\
\hline \multirow[t]{4}{*}{2} & \multirow[t]{4}{*}{ Treatment with steroids is done with? } & IV hydrocortisone $50 \mathrm{mg} \mathrm{q} 8$ hourly & 4 & 11 & $15(25.8)$ \\
\hline & & IV hydrocortisone $100 \mathrm{mg}$ q hourly & 2 & 28 & $30(51.7)$ \\
\hline & & Oral steroids & 0 & 1 & $1(1.7)$ \\
\hline & & IV continuous infusion of steroids. & 0 & 12 & $12(20.7)$ \\
\hline \multirow[t]{5}{*}{3} & \multirow[t]{5}{*}{ Retesting of adrenal function is done after? } & 5 days & 0 & 8 & $8(13.8)$ \\
\hline & & 1 week & 0 & 19 & $19(32.7)$ \\
\hline & & Once clinically stable & 4 & 17 & $21(36.2)$ \\
\hline & & After discharge & 2 & 5 & 7 (12.1) \\
\hline & & No response & 0 & 3 & 3 \\
\hline \multirow[t]{5}{*}{4} & \multirow[t]{5}{*}{ The duration of cortisol treatment is? } & 5 days & 1 & 8 & $9(1.5)$ \\
\hline & & 7 days & 3 & 17 & $20(34.5)$ \\
\hline & & 10 days & 0 & 4 & $4(6.9)$ \\
\hline & & 2 weeks & 0 & 3 & $3(5.2)$ \\
\hline & & Upto clinical improvement & 2 & 20 & $22(37.9)$ \\
\hline
\end{tabular}

insufficiency. While most of the endocrinologists felt that adrenal insufficiency should be routinely screened for in the critically ill, the intensivists felt that there was no need for a routine screening protocol.

Random serum cortisol was selected by $62 \%$ of the responders as the method for evaluating adrenal function in the critically ill. Among the endocrinologists the opinion seems to be split midway between random serum cortisol and $250 \mu \mathrm{g} \mathrm{ACTH} \mathrm{stimulation} \mathrm{test.} \mathrm{There}$ is clearly no agreement among the endocrinologists or the intensivists on the various cut off levels for diagnosis. Neither is there a clear consensus on the method followed for treatment of patients with adrenal insufficiency in the critical care unit.

\section{Discussion}

Relative adrenal insufficiency is a common manifestation in the critically ill. The cortisol levels although very high in absolute sense is relatively insufficient to control the inflammatory response. Important clinical clues for adrenal insufficiency in the 
critically ill include hemodynamic insufficiency despite adequate crystalloid replacement and ongoing evidence of inflammation without an obvious source. ${ }^{[1-3]}$

Laboratory evaluation of the cortisol levels in the critically ill has been a difficult task. Both very high values or the random serum cortisol and very low values have been shown to be associated with poor prognosis. ${ }^{[4,5]}$ The current assessment of adrenal insufficiency in the critically ill is predominantly based on a random serum cortisol and $250 \mu \mathrm{g} \mathrm{ACTH}$ stimulation test.

There is a definite correlation between the cortisol levels and the severity of critical illness. It is difficult to assess what level of cortisol is adequate response to stress. Proposed minimal levels of random serum cortisol have ranged from $10 \mu \mathrm{g} / \mathrm{dl}$ to $34 \mu \mathrm{g} / \mathrm{dl}$, but some studies have described that a cut off of $18 \mu \mathrm{g} / \mathrm{dl}$ best identifies patients with adrenal insufficiency. ${ }^{[6-8]}$

There is a lot of controversy surrounding the utility of the ACTH stimulation test and the procedure to be adopted for this test in the critically ill patient. Annane et al. (2000) ${ }^{[5]}$ in their landmark paper classified three prognostic groups based on the response to corticotropin stimulation test. One group had cortisol level at baseline greater than $34 \mu \mathrm{g} / \mathrm{dl}$ and peak stimulation with a difference greater than $9 \mu \mathrm{g} / \mathrm{dl}$ and it had a good prognosis. The second group had a baseline cortisol of $34 \mu \mathrm{g} / \mathrm{dl}$ and a peak stimulation difference greater than $9 \mu \mathrm{g} / \mathrm{dl}$ and this group had an intermediate prognosis. The third group had a baseline cortisol greater than $34 \mu \mathrm{g} / \mathrm{dl}$ and a peak stimulation difference $<9 \mu \mathrm{g} / \mathrm{dl}$ and this group had poor prognosis. ${ }^{[9]}$ A threshold of $18 \mu \mathrm{g} / \mathrm{dl}$ of serum cortisol $1 \mathrm{~h}$ after ACTH injection has been set as normal adrenal reserve. ${ }^{[10]}$ But this threshold has been challenged and said to be inappropriately low in critically ill patients. Critically ill patients with adequate adrenocortical reserve should raise their cortisol levels much higher than this to about $25 \mu \mathrm{g} / \mathrm{dll}$. Some studies such as the Abdu, Elhadd, Neary et al study which compared with the 1 and $250 \mu \mathrm{g}$ ACTH stimulation tests head to head did show some superiority of the $1 \mu \mathrm{g} \mathrm{ACTH}$ stimulation test over the $250 \mu \mathrm{g} \mathrm{ACTH}$ stimulation test, but there is no strong evidence to support one over the other. ${ }^{[11]}$ It has also been argued that the change in cortisol level after stimulation of $9 \mu \mathrm{g} / \mathrm{dl}$ should not be used as the criteria for evaluation adrenal function as it only indicated the adrenal reserve and not the adrenal function.

The next facet to be considered in this regard is the treatment of these patients. McKee and Finlay ${ }^{[12]}$ randomized 18 patients with diagnosed adrenal insufficiency to glucocorticoid treatment versus placebo. One of the eight steroid treated patients died compared to nine of the 10 placebo treated patients. ${ }^{[12]}$ Further evidence for benefit of corticosteroid treatment in the critically ill came from Bollaret et al and Briegel et al studies. ${ }^{[13,14]}$ In these studies although a random serum cortisol was obtained the treatment was not stratified based on the cortisol levels. In the study group there was significant reduction in mortality and morbidity. Annane et al randomized 200 critically ill patients to steroid therapy versus placebo. There was a significant $30 \%$ reduction in the mortality among the steroid treatment group. ${ }^{[15]}$ The dose of $100 \mathrm{mg}$ IV $8^{\text {th }}$ hourly was recommended. In a meta analysis conducted by Annane et al. it was shown that long courses of low dose corticosteroids reduced mortality in 28 days in intensive care units and it does not adversely alter the risk of gastro duodenal bleeding, hyperglycemia or super infections. ${ }^{[16]}$

In this background this survey was conducted to assess the level of knowledge of this evidence among the practicing endocrinologists and intensivists and their current practice patterns. What emerges from this survey is the fact that there is no clear consensus among the endocrinologists or the intensivists about adrenal insufficiency in the critically ill. There is a wide variability in their practice patterns.

There are several probable reasons for this variability. The first factor, which needs to be looked into is the sample of the physicians who responded to these questionnaires. Only six endocrinologists in the city answered and turned in the questionnaires. The small numbers probably have an effect on the results. Among the intensivists some of them were trained in critical care medicine. Most of them were intensivists in practice with no formal training in intensive care medicine. Some of them were residents and registrars in training. This is probably the reason for the wide variability in the responses. The second factor, which is important, is the lack of consensus meetings and hospital protocol framing committees, which can set standard treatment protocols specific to each hospital. If such systems could exist this 
would standardize the treatment of patients across the board and it also gives adequate time for the involved physicians to review the topics under consideration. The third important factor is the lack of inter-disciplinary meetings and discussions where the members of different specialties could get together and discuss topics of common interest. This would help to make the practice patters uniform in field such as adrenal insufficiency in critically ill where the treatment could be managed by either the endocrinologists or the intensivists.

\section{Conclusion}

From this study the authors suggest that there is a need to develop standard diagnostic and treatment guidelines for adrenal insufficiency in the critically ill and make it available to the endocrinologists and intensivists so as to evolve a uniform practice pattern. This could be done by organizing interdisciplinary meetings in the hospitals where all specialists could participate and contribute to the formation of the guidelines.

\section{Acknowledgements}

The authors acknowledge the contributions of Mrs. Meena lyer for her administerial help, Ms. Sripriya Rao and Ms. Uma Kanniappan for their secretarial help and Dr Satish for his help in data collection.

\section{References}

1. Cooper MS, Stewart PM. Corticosteroid insufficiency in acutely ill patients. New Engl J Med 2003;348:727-34.

2. Lamberts SW, Bruining HA, de Jong FH. Corticosteroid therapy in severe illness. N Engl J Med 1997;337:1285-92.

3. Burchard K. A review of the adrenal cortex and severe inflammation: Quest of the "Eucorticoid" state. J Trauma 2001;51:800-14.

4. Sibbald WJ, Short A, Cohen MP, Wilson RF. Variations in adrenocortical responsiveness during severe bacterial infections: Unrecognized adrenocortical insufficiency in severe bacterial infections. Ann Surg 1977;186:29-33.

5. Annane D, Sebille V, Troche G, Raphael JC, Gajdos P, Bellissant E. A 3-level prognostic classification in septic hock based on cortisol levels and cortisol response to corticotropin. JAMA 2000;283:1038-45.

6. Barquist E, Kirton O. Adrenal insufficiency in the surgical intensive care unit patient. J Trauma 1997;42:27-31.

7. Kidess Al, Caplan RH, Reynertson RH, Wickus GG, Goodnough DE. Transient corticotropin deficiency in critical illness. Mayo Clin Proc 1993;68:435-41.

8. Bouachour G, Tirot P, Varache N, Govello JP, Harry P, Alquier P. Hemodynamic changes in acute adrenal insufficiency. Intensive Care Med 1994;20:138-41.

9. Annane D, Sebille V, Troche G, Raphael JC, Gajdos P, Bellissant E. A 3 level prognostic classification in Septic Shock based on Cortisol levels and Cortisol response to Corticotropin. JAMA 2000;283:1038-45.

10. Streeten $\mathrm{DH}$. What test for hypothalamic-pituitary adrenocortical insufficiency? Lancet 1999;354:179-80.

11. Abdu TA, Elhadd TA, Neary R, Clayton RN. Comparison of the low dose short Synacthen test (1 microg), the conventional dose short Synacthen test (250 microg) and insulin tolerance test for assessment of the hypopthalamo-pituitary-adrenal axis in patients with pituitary disease. J Clin Endocrinol Metab 1999;84:838-43.

12. McKee JI, Finlay WI. Cortisol replacement in the severely stressed patients (Letter). Lancet 1983;1:484.

13. Bollaret PE, Charpentier C, Levy B, Debouverie M, Audibert G, Larcan A. Reversal of late septic shock with supraphysiological doses of hydrocortisone. Crit Care Med 1998;26:645-50.

14. Briegel J, Frost J, Haller M, Schelling G, Kilger E, Kuprat G, et al. Stress doses of hydrocortisone reverse hyperdynamic septic shock: A prospective, randomized, double blind, single center study. Crit Care Med 1999;27:723-32.

15. Annane D. Effects of the combination of hydrocortisone and fluodrocortisone on mortality in septic shock. Crit Care Med 2000;28:A46.

16. Annane D, Bellissant E, Bollaert PE, Briegel J, Keh D, Kupfer Y. Corticosteroids for severe sepsis and septic shock: A systematic review and meta-analysis. BMJ 2004;329:480.

Source of Support: Nil, Conflict of Interest: None declared. 